\title{
Impacts of Changes in Sea Ice and Heat Flux on Arctic Warming
}

\author{
Yong Cao', Lingen Bian'²*, Jinping Zhao ${ }^{1}$ \\ ${ }^{1}$ Ocean University of China, Qingdao, China \\ ${ }^{2}$ Chinese Academy of Meteorological Sciences, Beijing, China \\ Email: ‘bianlg@cma.gov.cn
}

How to cite this paper: Cao, Y., Bian, L.G. and Zhao, J.P. (2019) Impacts of Changes in Sea Ice and Heat Flux on Arctic Warming. Atmospheric and Climate Sciences, 9, 84-99.

https://doi.org/10.4236/acs.2019.91006

Received: October 22, 2018

Accepted: December 22, 2018

Published: December 25, 2018

Copyright $\odot 2019$ by authors and Scientific Research Publishing Inc. This work is licensed under the Creative Commons Attribution International License (CC BY 4.0).

http://creativecommons.org/licenses/by/4.0/

c) (i) Open Access

\begin{abstract}
The reduction of Arctic sea ice has enhanced the sea-ice-air interaction in the Arctic atmospheric boundary layer, especially the increase in sea-air heat flux in autumn. Changes in radiation and heat flux and the role of sea-ice-air interactions in climate change in the central Arctic were analyzed and evaluated on the basis of the observation data of ice stations during the six Chinese Arctic Research Expeditions. The albedo is high in the Arctic sea-ice surface except the melting process. Overall, the Arctic sea-ice surface can absorb radiation energy, which is much lower than that absorbed by mid-latitude surfaces. Consequently, a relatively weak turbulence exchange occurred between the sea-ice surface and the atmosphere. Further estimates of the surface heat budget in the Arctic are obtained using eddy correlation and flux-profile method. The results are representative of the heat balance and ice-air interactions in the central Arctic Ocean. In the Arctic, changes in heat flux displayed notable interdecadal characteristics, similar to the change of sea-ice extent. The heat flux in September of each year in 2001-2014 was considerably higher compared with that in 1979-2000, particularly at the edges of the central Arctic Ocean. In September of each year in 1979-2014, the sea-ice extent was remarkably negatively correlated to the heat flux (sensible heat flux + latent heat flux), and the heat flux was considerably positively correlated to the atmospheric temperature at $2 \mathrm{~m}$ above sea level. This result demonstrates that a reduction of Arctic sea ice will lead to changes in heat flux, thereby warming the atmosphere and increasing the temperature of the atmospheric boundary layer over the Arctic. In addition, this impact is long-lasting.
\end{abstract}

\section{Keywords}

Arctic, Sea Ice, Radiation Flux, Heat Flux, Sea-Ice-Air Interactions

\section{Introduction}

During global warming in recent decades, the heat content of all oceans has in- 
creased continuously [1] [2] [3] [4] [5], accompanied by an increase in the air-sea heat flux [6]. This phenomenon is particularly pronounced in the Arctic. Since the twenty-first century, the Arctic warming rate has been twice the average global warming rate. This phenomenon is referred to as "Arctic amplification" [7] [8]. The decrease in the area and density of Arctic sea ice has strengthened sea-ice-air interactions in the atmospheric boundary layer over the Arctic, particularly causing an increase in the air-sea heat flux and a decrease in the stability of the boundary layer in fall and early winter [9]. The reduction of Arctic sea ice has resulted in an increase in the amount of shortwave solar radiation entering the ocean, which is the main energy source associated with the "Arctic amplification" process. Numerical simulations have demonstrated that $80 \%$ of the increase in energy of the upper layer of the Arctic Ocean originates from the sea surface heat flux [10]. Considerable interannual differences occur in the seasonal ice-free area in the Arctic, resulting in relatively large seasonal and interannual fluctuations in the air-sea heat flux, which contribute to nearly one-third of long-term changes in the heat content of the entire Arctic Ocean [11]. However, at present, trends in Arctic sea-ice changes simulated by most climate models contain relatively large errors [12] [13] [14] [15]. This is mainly due to the lack of investigations on key ocean processes in the Arctic and an insufficient understanding of the distribution of heat among the ocean, sea ice, and atmosphere.

In 1998, the US conducted the Surface Heat Budget of the Arctic Ocean study to observe the energy balance among the ocean, ice, and atmosphere [16]. The European Union organized and implemented the International Polar Year Collaborative Project, which focuses on the Arctic [17]. Given the lack of fixed meteorological observation stations in the central Arctic Ocean, atmospheric vertical sounding data for this region are scarce. Research on the structural changes in the troposphere and their trends [18] [19] relies primarily on reanalysis data. However, results are difficult to validate by comparing them to observation data. In particular, sounding data for the central Arctic Ocean are limited. Since 1999, China has organized and conducted eight scientific expeditions to the Arctic Ocean and obtained observation test data for the vertical structure of the atmosphere and sea-ice-air interactions in summer. These data allow us to have a preliminary understanding of the characteristics of the atmospheric boundary layer over regions in the Arctic that differ in sea-ice density [20]-[26]. The continuous reduction of sea-ice extent enables the Chinese Arctic Research Expedition to reach the central Arctic Ocean $80^{\circ} \mathrm{N}$ since 2008 [27] [28] [29] [30]. This condition provides an important basis for studying the structure of the troposphere and boundary layer over high-latitude regions of the Arctic Ocean.

On the basis of observation data for the atmospheric boundary layer near the ice layer in the sea-ice region of the Arctic Ocean, Bian et al. [31] used a flux-profile method and a model to estimate and simulate the energy balance component and turbulence exchange parameter of the sea-ice surface and ana- 
lyze the changes in the heat balance component of Arctic sea ice. Intense interactions occur among relatively strong, warm, and wet air currents originating from high altitudes, and cold surface layer air over the ice surface forms a strong wind shear, as well as temperature and humidity inversion processes. These processes can effectively prevent heat and matter exchange between the atmosphere and sea-ice surface [20] [21] and break large blocks of sea ice in the Arctic Ocean at high latitudes [23]. The variation characteristics of the height of the atmospheric boundary layer over the Arctic Ocean were studied [25]. Furthermore, the sea-ice changes considerably affect the structure of the atmospheric boundary layer [26]. In this study, we focus on the characteristics of the sea-ice surface radiation flux and sea-air turbulence heat flux in the Arctic, and their effects on the Arctic warming.

\section{Data and Methods}

All ice stations were established in the central Arctic Ocean $\left(75^{\circ} \mathrm{N}-87^{\circ} \mathrm{N}, 123^{\circ} \mathrm{E}\right.$ $-143^{\circ} \mathrm{W}$ ) in summer during the Chinese Arctic Research Expeditions. Ice station observations were conducted for $1-2$ weeks during the first to fourth expeditions; a drifting automatic meteorological station observation system was used during the fifth and sixth expeditions and, as a result, long-time-series observation data were obtained [9]. Changes in several parameters of the central Arctic Ocean, including upwelling and downwelling shortwave and longwave radiation, sea-ice albedo, net radiation, and heat transfer in ice, were evaluated on the basis of the ice station observation data obtained during the six expeditions in 1999-2014. The radiation and heat balance equations are as follows:

$$
\begin{aligned}
& R_{n}=S_{t}-S_{g}+L_{a}-L_{g}, \\
& R_{n}=H+L E+G+M,
\end{aligned}
$$

where $R_{n}$ is the net radiation, $S_{t}$ denotes the downwelling shortwave radiation, $S_{g}$ represents the reflected shortwave radiation, $L_{a}$ indicates the atmospheric longwave radiation, $L_{g}$ refers to the upwelling longwave radiation (all the radiation values used are actual measurements), $H$ is the sensible heat flux, $L E$ denotes the latent heat flux, $G$ indicates the heat flux in ice, and $M$ represents the heat flux absorbed (released) when ice melts (is formed). $H$ and $L E$ are calculated on the basis of vortex-related turbulence observation data, and $G$ and $M$ are estimated by solving Equation (2) [32].

Sensible heat flux and latent heat flux are important parameters for analyzing the interaction of sea-ice-air. The surface heat budget can be directly obtained by eddy correlation method, or can be obtained by the flux-profile method which is formed by the observed temperature and humidity profiles and similar theoretical empirical formulas [33]. The precision of the heat flux using eddy correlation method is better than that using flux-profile method. In this paper, the flux-profile method was used during the first, the second, the fifth and the sixth expeditions, and the eddy correlation method was used during the third and the fourth expeditions. 


\section{Characteristics of the Sea-Ice Surface Radiation Flux in the Arctic}

Figure 1 shows the total and reflected radiation flux time-series data measured at the ice stations during the six expeditions. Observations were conducted during the polar day period in the Arctic. Considerable diurnal and interdiurnal changes were observed in total and reflected radiation. The radiation flux reached its maximum at noon and minimum at midnight. The total radiation flux on a sunny day was remarkably higher (up to twice) than that on a cloudy day. A relatively large difference in radiation flux in different years exists due to variations in observation time, observation point latitude, and solar zenith angle.

The average net shortwave radiation flux $\left(5.1-46.2 \mathrm{~W} / \mathrm{m}^{2}\right.$; Table 1$)$, closely related to the weather and properties of the underlying surface during the observation period, varied remarkably among the six observation periods. For these periods, the average net shortwave radiation flux average was $22.6 \mathrm{~W} / \mathrm{m}^{2}$.
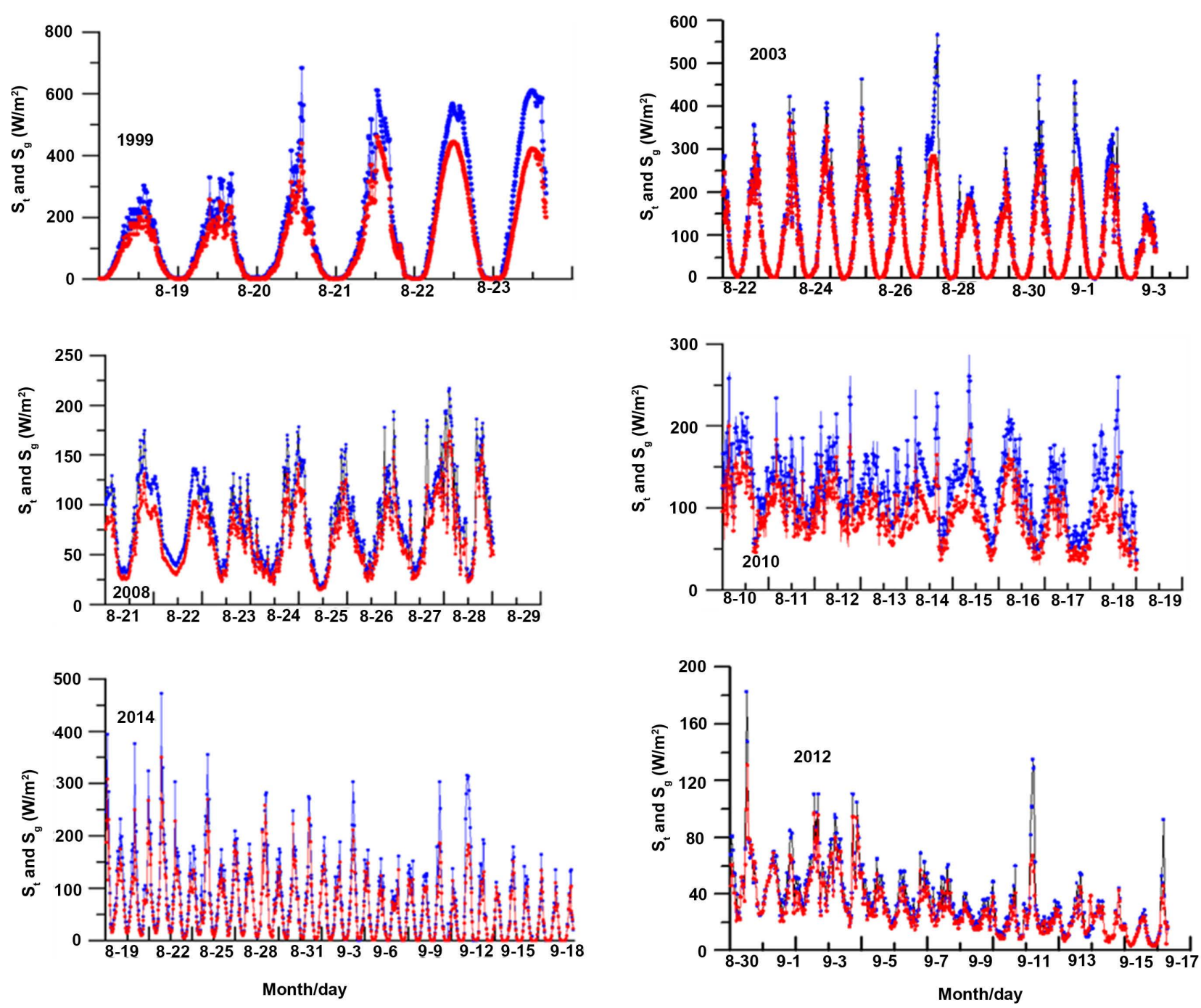

Figure 1. Total $S_{t}$ (blue) and reflected $S_{g}(\mathrm{red})$ radiation $\left(\mathrm{W} / \mathrm{m}^{2}\right)$ time-series data measured at the ice stations during Chinese Arctic Research Expeditions. 
Table 1. Average radiation flux parameter measured at the ice stations during the six Chinese Arctic Research Expeditions.

\begin{tabular}{ccccccc}
\hline Year & 1999 & 2003 & 2008 & 2010 & 2012 & 2014 \\
\hline Date & $08.19-08.23$ & $08.22-09.03$ & $08.21-08.29$ & $08.10-08.19$ & $08.30-09.17$ & $08.19-09.18$ \\
Shortwave radiation flux $\left(\mathrm{W} / \mathrm{m}^{2}\right)$ & 46.2 & 18.7 & 18.0 & 33.2 & 5.1 & 14.2 \\
Longwave radiation flux $\left(\mathrm{W} / \mathrm{m}^{2}\right)$ & 15.9 & 8.6 & 7.2 & 8.5 & 3.1 & 11.4 \\
Net radiation flux on the surface of sea ice $\left(\mathrm{W} / \mathrm{m}^{2}\right)$ & 30.3 & 10.1 & 10.8 & 24.7 & 2.0 & 2.8 \\
Albedo & 0.74 & 0.83 & 0.79 & 0.74 & 0.86 & 0.81 \\
\hline
\end{tabular}

An insubstantial diurnal change but substantial interdiurnal change occurred in longwave radiation on snow surface and atmospheric (Figure 2). The difference of longwave radiation between atmospheric and snow surface was small due to relatively small temperature difference on cloudy and snowy days. A relatively frequent cloudy and snowy weather exists in the Arctic, resulting in considerable fluctuations in longwave radiation. The average net longwave radiation fluxes were $15.9,8.6,7.2,8.5,3.1$, and $11.4 \mathrm{~W} / \mathrm{m}^{2}$ (Table 1), averaging $9.6 \mathrm{~W} / \mathrm{m}^{2}$. As shown in Figure 2, the sea-ice surface longwave radiation was higher than the downwelling atmospheric counter-radiation, and radiation cooling mainly occurred on the sea-ice surface.

Albedo, the ratio of reflected radiation to total reflection, is an important parameter in atmospheric and sea-ice models. Figure 3 shows the albedo time-series data measured during the six expeditions. A considerable interdiurnal change was observed in the albedo of the Arctic sea-ice surface. In addition, a relatively pronounced diurnal change was observed in the albedo of the Arctic sea-ice surface on clear or cloudy days. Generally, the sea-ice surface has a relatively high albedo (up to over 0.95 ) when the solar zenith angle reaches its maximum. The albedo of the sea-ice surface decreases (to as low as approximately 0.5 ) when sea ice melts. Ice-melted water often permeates the ice, thereby altering the ice structure. This process reduces the albedo of the sea-ice surface. The average albedo measured during the six expeditions ranged from 0.74 to 0.86 , averaging approximately 0.8 (Table 1). Sea ice has a considerably higher albedo than seawater. As a result of the reduction of sea ice and the increase in the area of open waters, the ocean absorbs additional heat, which further accelerates sea-ice melting. This positive feedback process of Arctic sea ice is also referred to as sea ice temperature feedback [34].

Evaluating changes in radiation balance plays a vital role in improving computational schemes for turbulence flux and boundary layer parameterization. In Figure 4, the net radiation flux on the surface of sea ice was calculated using Equation (1). Similar to solar radiation, considerable diurnal and interdiurnal changes occurred in net sea-ice surface radiation flux in the Arctic. The average net radiation fluxes on the surface of sea ice measured during the six expeditions to the Arctic were $30.3,10.1,10.8,24.7,2.0$, and $2.8 \mathrm{~W} / \mathrm{m}^{2}$ (Table 1), averaging 13.5 $\mathrm{W} / \mathrm{m}^{2}$. For the ice stations implemented near $75^{\circ} \mathrm{N}$, the average net radiation 

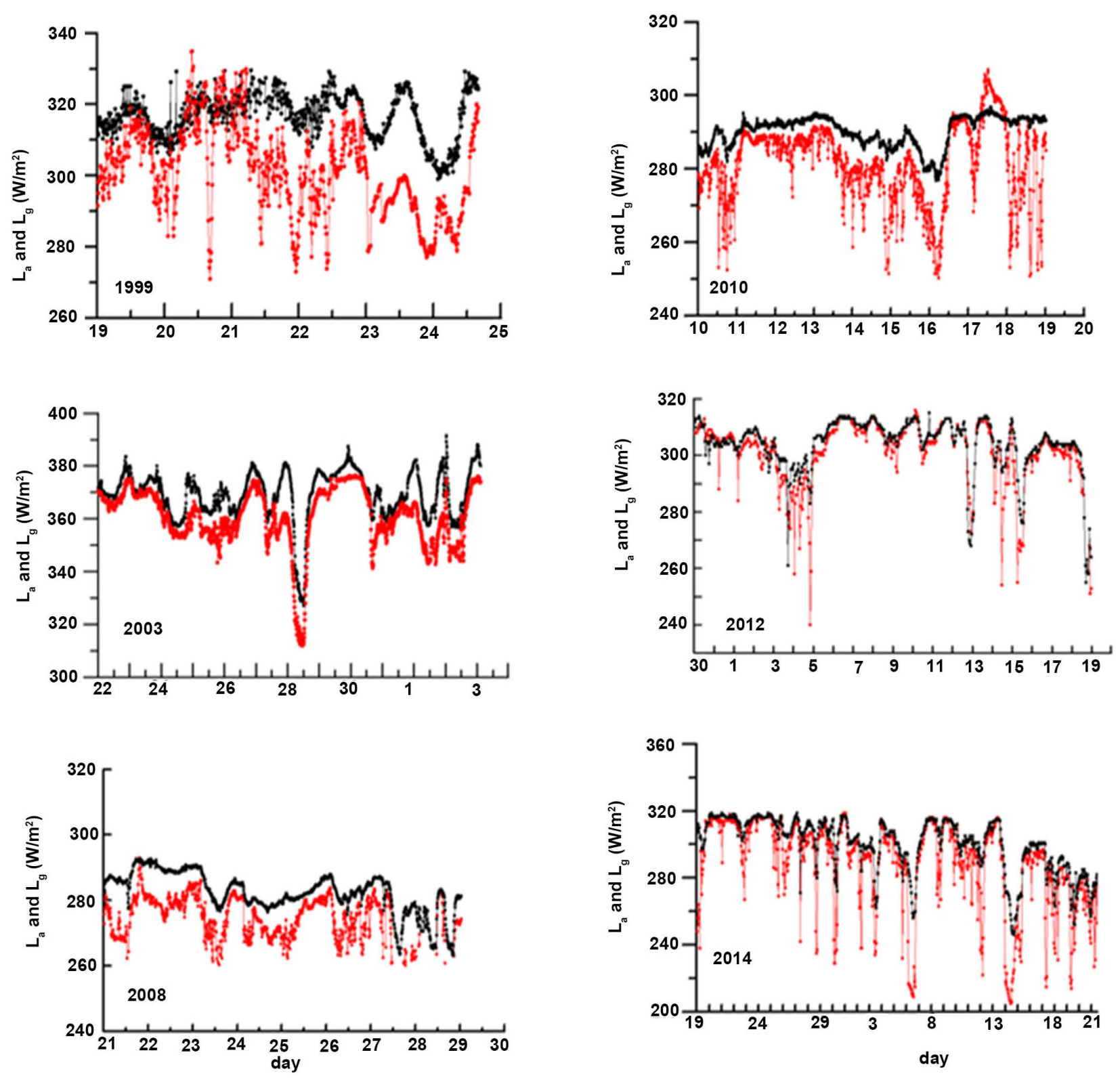

Figure 2. Atmospheric $L_{a}$ (red) and sea-ice surface $L_{g}$ (black) longwave radiation flux $\left(\mathrm{W} / \mathrm{m}^{2}\right)$ time-series data measured at the ice stations during the six Chinese Arctic Research Expeditions.

flux measured was the highest in 1999. The average net radiation fluxes measured in 2012 and 2014 were relatively low due to the relatively high albedo of the sea-ice surface and weather factors.

Overall, the net radiation flux and albedo are not only related with the latitude but also the properties of the underlying surface. The solar radiant energy absorbed by the surface of the sea ice is very small, and most of it is exchanged with the atmosphere by long-wave and turbulent. So the Arctic sea-ice surface can absorb radiation energy, but which is much lower than that absorbed by mid-latitude surfaces. Consequently, a relatively weak turbulence exchange occurred between the sea-ice surface and the atmosphere. 

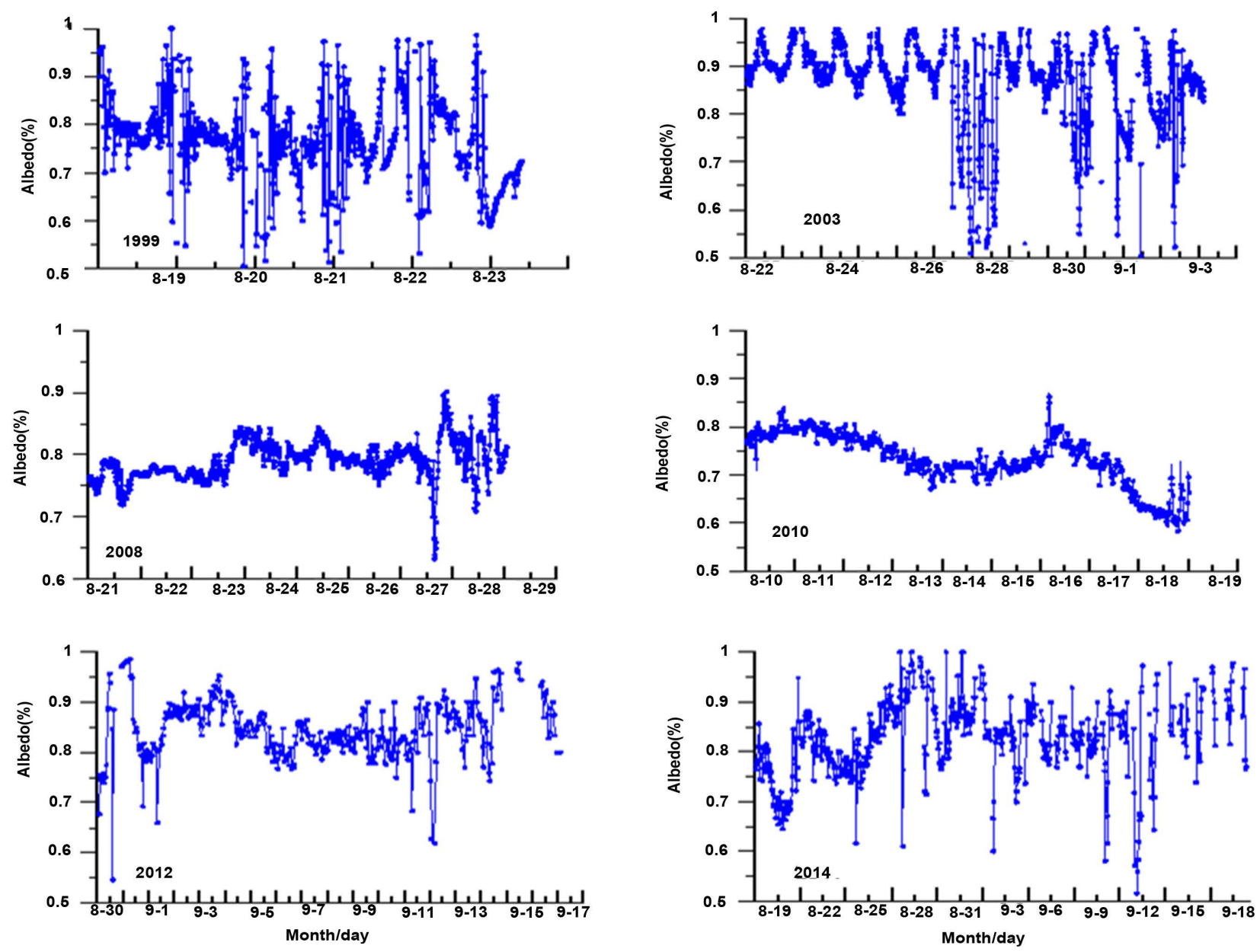

Figure 3. Albedo $(\alpha)$ time-series data measured at the ice stations during the six Chinese Arctic Research Expeditions.

\section{Sea-Air Turbulence Heat Flux in the Arctic}

To quantitatively evaluate the contribution of sea-ice-air interactions caused by the rapid reduction of Arctic sea ice to temperature increases, ice-air heat exchange was analyzed on the basis of the turbulence flux determined by observing vortices at the ice stations during the third and fourth expeditions to the Arctic. Figure 5 shows the average diurnal changes in heat balance flux measured at the Arctic ice stations ( $Q S$ is the sum of the heat flux absorbed by ice melting and the heat transfer flux in ice, $S H$ represents sensible heat). The average diurnal changes in the heat balance component determined at the Arctic ice stations in 2008 and 2010 displayed similar patterns. A part of the net radiation absorbed by the sea-ice surface during the day heated the atmosphere in the form of turbulence, and other heats were consumed by ice melting and transferred to the ice layer. At night, a balance existed between radiation cooling and the heat flux released by ice. Substantial diurnal changes occurred in net radiation, the heat flux absorbed by ice melting, and the heat transfer flux in ice, whereas unsubstantial diurnal changes were observed in sensible and latent heat fluxes. This result suggests that the radiation energy absorbed by the sea-ice surface was mainly 

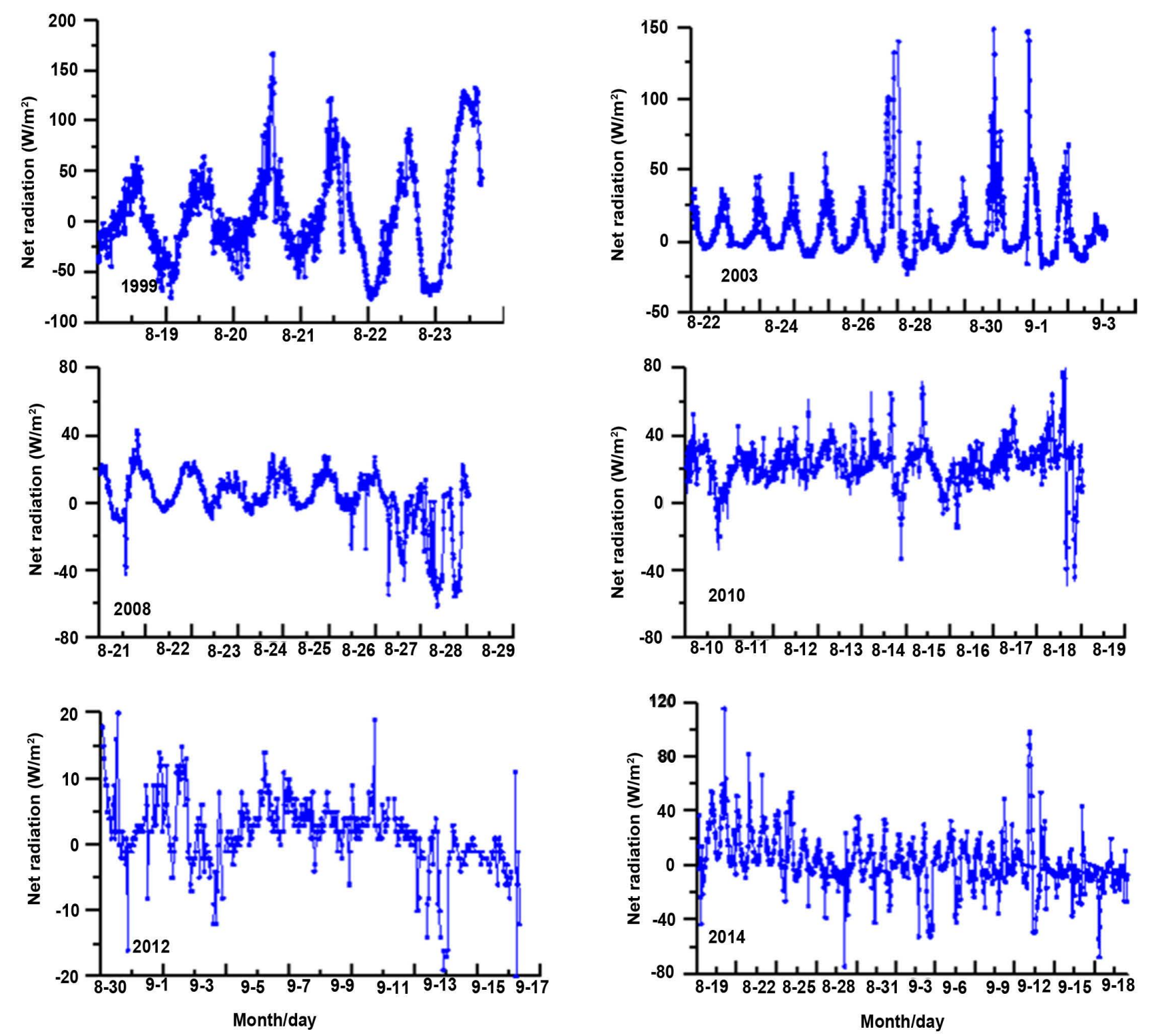

Figure 4. Net radiation flux on the surface of sea ice during the six Chinese Arctic Research Expeditions.

consumed by ice melting and heat transfer in ice, and only a small proportion participated in heat exchange with the atmosphere. The average sensible fluxes measured at the ice stations during the 2008 and 2010 observation periods were -1.51 and $-1.89 \mathrm{~W} / \mathrm{m}^{2}$, and the average latent heat fluxes were 2.41 and 1.5 $\mathrm{W} / \mathrm{m}^{2}$, respectively. A negative sensible heat flux indicates that the atmosphere transfers heat to the sea-ice surface. A positive latent heat flux indicates that the sea-ice surface transfers heat to the atmosphere. A heat inversion structure was observed in the surface layer over the sea ice at the Arctic ice stations during each of the six expeditions. The surface layer temperature was greater than $0^{\circ} \mathrm{C}$ also occurred during the polar day period, which helped the atmosphere transfer heat to the sea-ice surface and helped the latent heat released by ice and snow melting warm the atmosphere. 

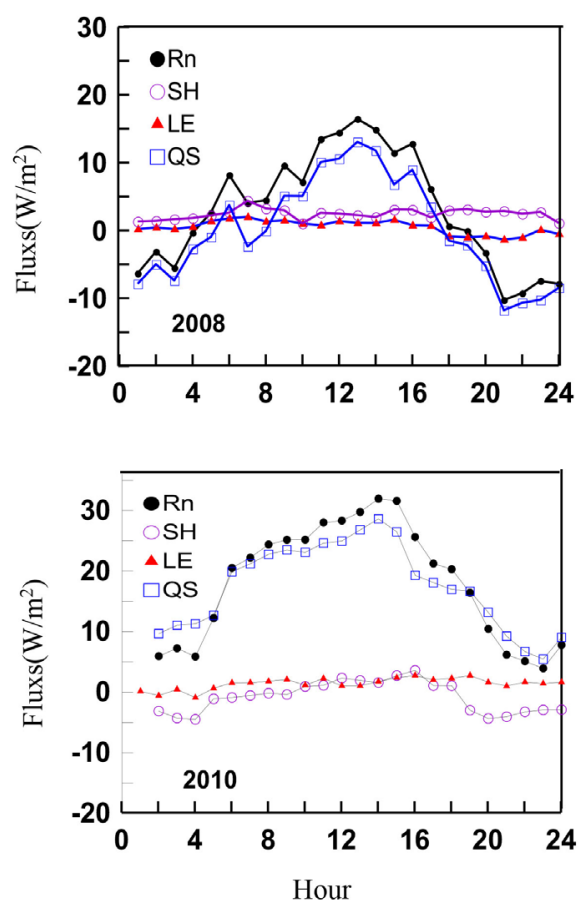

Figure 5. Average diurnal changes in net radiation flux $(R \mathrm{n})$, sensible heat $(S H)$, latent heat flux $(L E)$ and heat flux released by ice melting and heat transfer flux in ice (QS) measured at the ice stations between August 21 and 29, 2008 (top), and between August 10 and 19, 2010 (bottom).

Ice stations were established at the edges of large blocks of sea ice surrounded by a large area of ice-free open water during each of the six expeditions to the Arctic. Given that the radiation energy absorbed by the sea surface is higher than that absorbed by the sea-ice surface, a relatively strong turbulence exchange occurs between the sea surface and atmosphere. On the basis of the ice station observations during the first expedition to the Arctic, the net radiation energy absorbed by the sea surface was four times that absorbed by the sea-ice surface, and the sea surface transferred considerably more sensible and latent heat than the sea-ice surface [35]. With the rapid reduction of Arctic sea ice, the analysis of the ice-air heat exchange process is only one component of the research on the mechanism by which sea-air-ice interactions affect climate change in the Arctic. Understanding the thermal and momentum interactions between the ice-free waters of the Arctic Ocean and the atmosphere is necessary. The smallest sea-ice extent in the Arctic Ocean occurs in September, which is also when the ice-free area is the largest in the Arctic Ocean. Analyzing temporal and spatial changes in heat flux in September can help in understanding the basic pattern of the heat exchange between the sea ice and atmosphere and between the ocean and atmosphere. Thus, on the basis of the reanalysis data for September of each year in 1979-2014, the temporal and spatial changes in sensible and latent heat fluxes in the region $60^{\circ} \mathrm{N}$ were analyzed in this study to understand the role of sea-air-ice interactions caused by the rapid reduction of Arctic sea ice in climate change. 
Changes in the Arctic sea-ice extent in 1979-2014 can be approximately divided into two stages (Figure 6). Before 2000, the trend in changes in the sea-ice extent was unclear. After 2000, the sea-ice extent displayed a remarkable decreasing trend. Changes in the sea-ice extent showed notable interdecadal characteristics in 1979-2014. To analyze the interdecadal changes in heat flux in the Arctic, the spatial distributions of sensible and latent heat flux anomalies in the Arctic region $60^{\circ} \mathrm{N}$ in September of each year in the periods 1979-2000 and 2001-2014 were plotted. This process was based on the sensible and latent heat reanalysis grid data for the Arctic for September of each year in 1979-2014 (http://nsidc.org/data/docs/noaa/) as well as the meteorological reanalysis data of the same period (http://www.cdc.noaa.gov) (Figure 7). By comparing the distribution of heat flux anomalies during the two stages, regions with positive sensible and latent heat flux anomalies in 2001-2014, when a notable reduction of sea ice occurred, increased in size compared with those in 1979-2000, particularly at the edges of the Arctic Ocean. In most regions of the central Arctic Ocean, negative sensible heat flux anomalies and positive latent heat flux anomalies mainly occurred. However the changes of heat flux anomalies shown the interdecadal characteristics similar to the change of sea-ice extent. It is demonstrated that reduction of sea ice can cause albedo changes and increase heat flux from ocean to the atmosphere. Therefore changes in atmospheric heat transport may be an important reason of the recent Arctic temperature amplification.

Figure 8 reflects not only interdecadal but also interannual changes in sensible and latent heat fluxes. Before 1995, the sensible heat flux fluctuated within a range of low values and its minimum (approximately $-15 \mathrm{~W} / \mathrm{m}^{2}$ ) occurred in September 1985. After 1995, the sensible heat flux increased, on average, by approximately $5 \mathrm{~W} / \mathrm{m}^{2}$ and changed every year. Before 1995, the latent heat flux also fluctuated within a range of low values, and its minimum (approximately 16 $\mathrm{W} / \mathrm{m}^{2}$ ) occurred in 1992. After 1995, the latent heat flux increased, on average, by approximately $3 \mathrm{~W} / \mathrm{m}^{2}$ but increased remarkably after 2002, and its changes

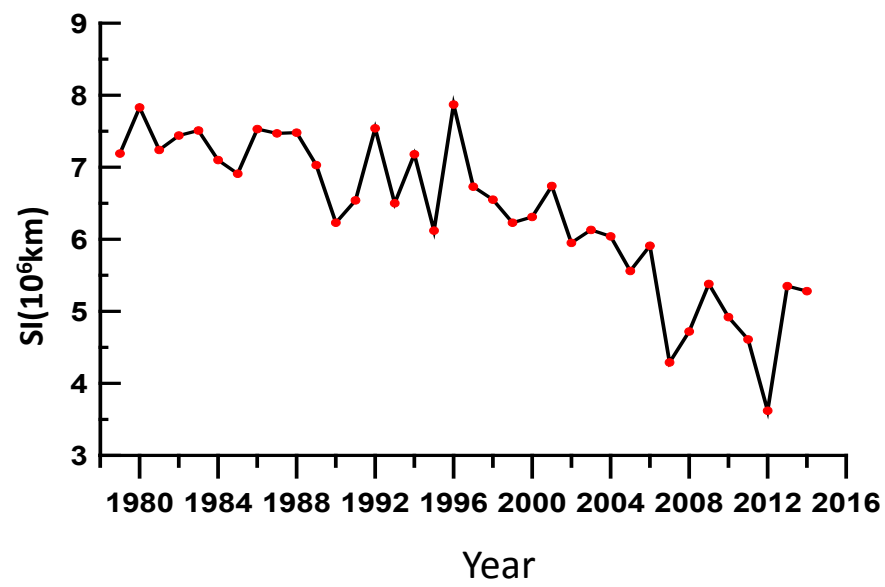

Figure 6. Time-series of average sea ice extent (SI) for September of each year in 1979-2014. 
Anomaly sensible flux from September 1979 to 2000
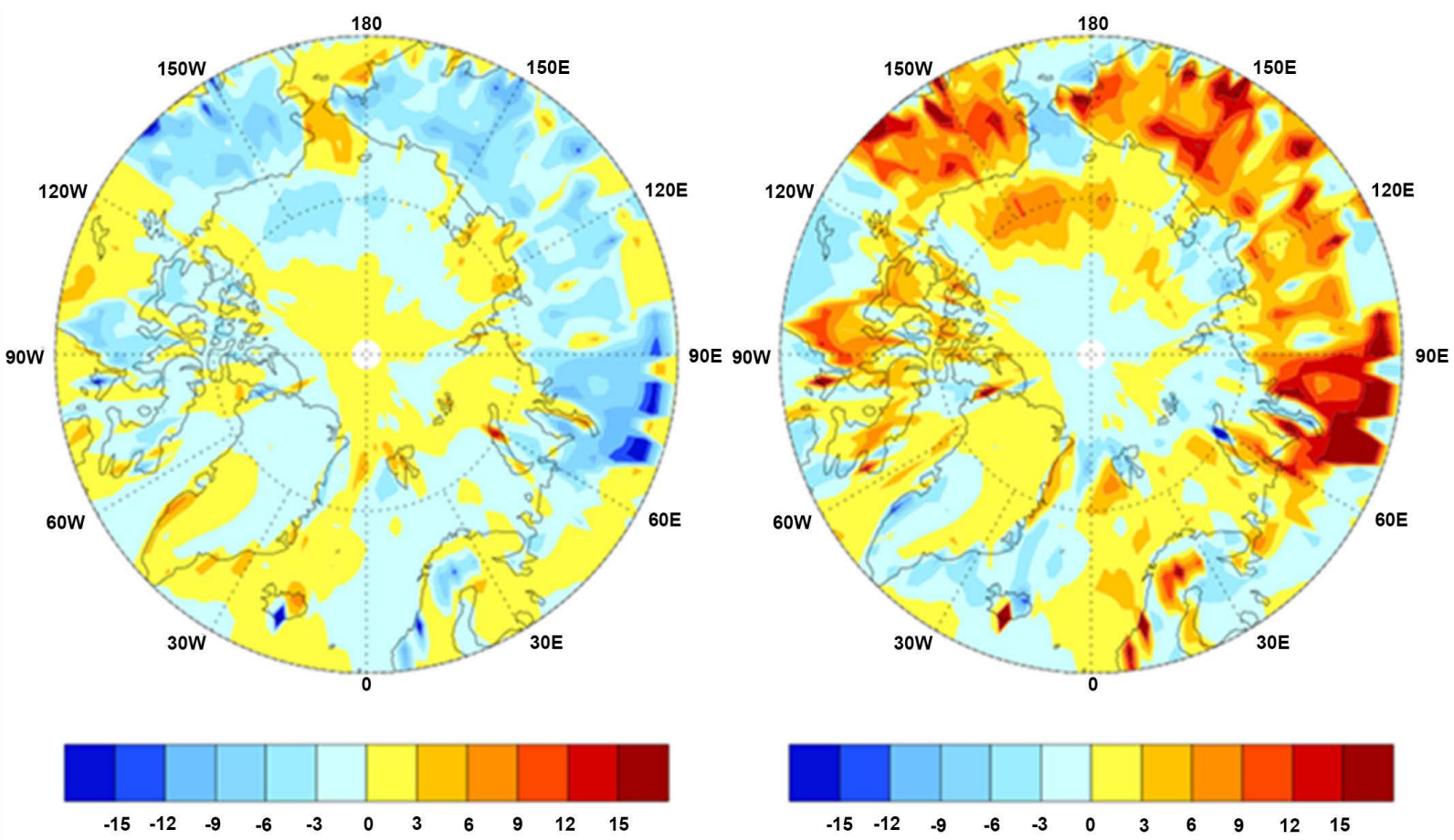

Anomaly latent heat flux from September 1979 to 2000

Anomaly latent heat flux from September 2001 to 2014
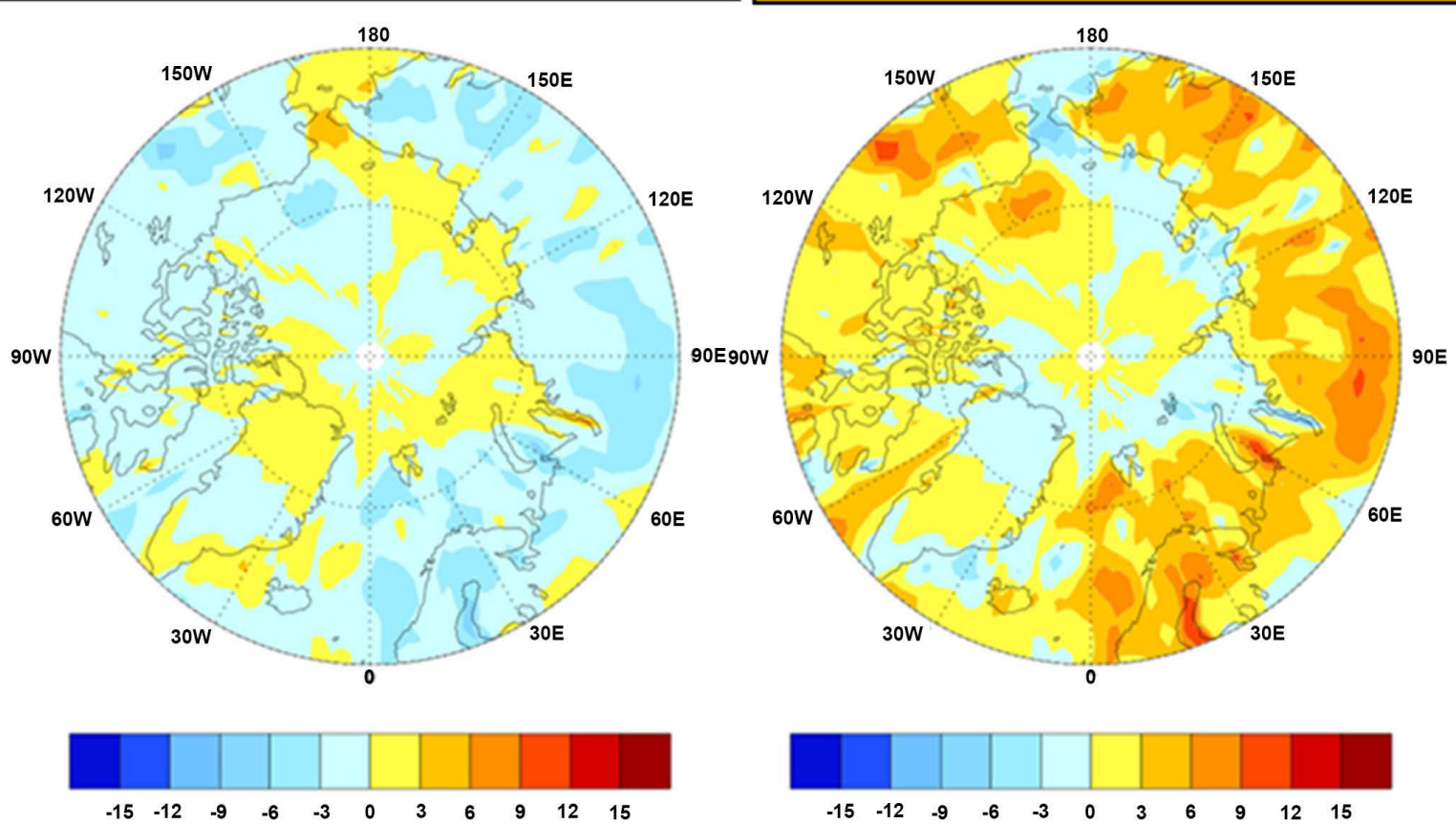

Figure 7. Spatial distribution of sensible and latent heat flux anomalies $\left(\mathrm{W} / \mathrm{m}^{2}\right)$ in September of each year in 1979-2000 and 2001-2014. 

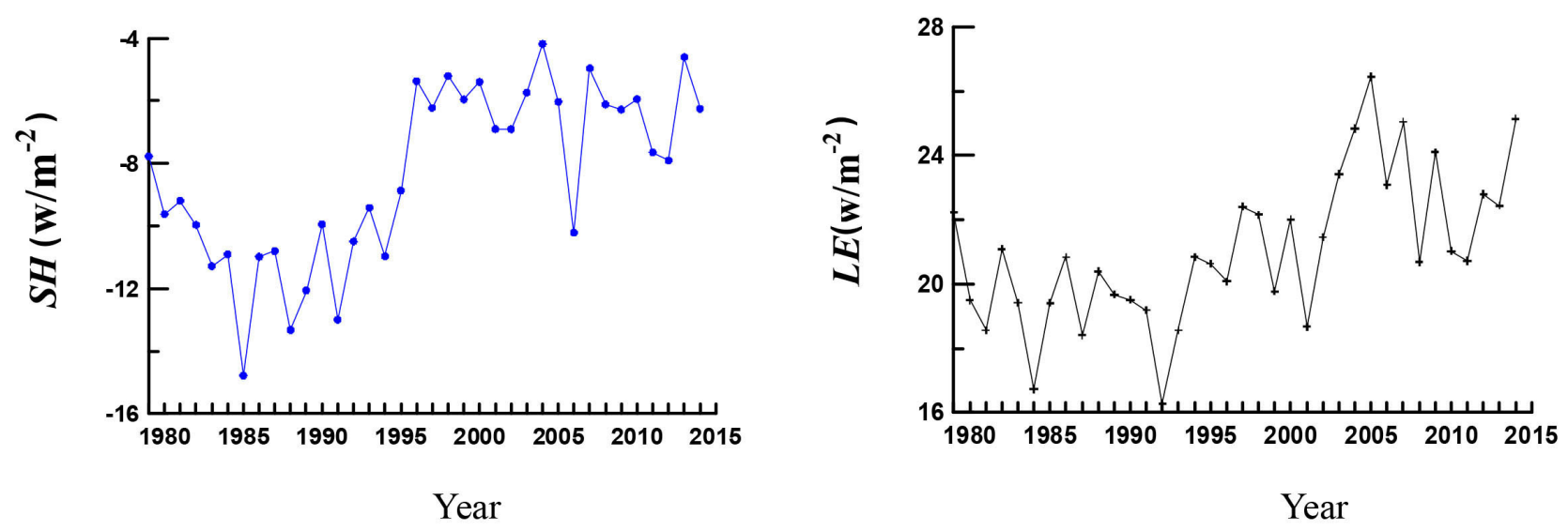

Figure 8. Average sensible heat flux $(S H)$ and latent heat flux $(L E)$ time-series data for the region $60^{\circ} \mathrm{N}$ for September of each year in 1979-2014.

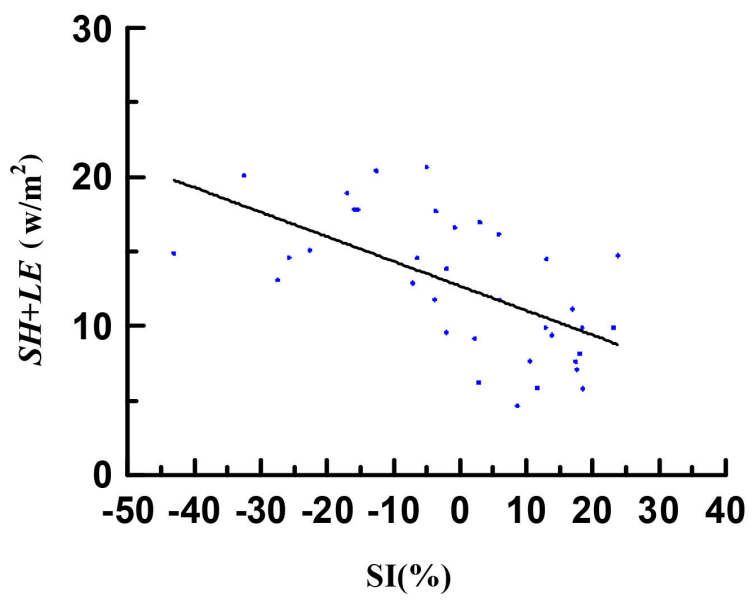

Figure 9. Correlation between average heat flux $(S H+L E)$ and percentage (\%) of average sea ice extent (SI) anomalies in the region $60^{\circ} \mathrm{N}$ in September of each year in 1979-2014.

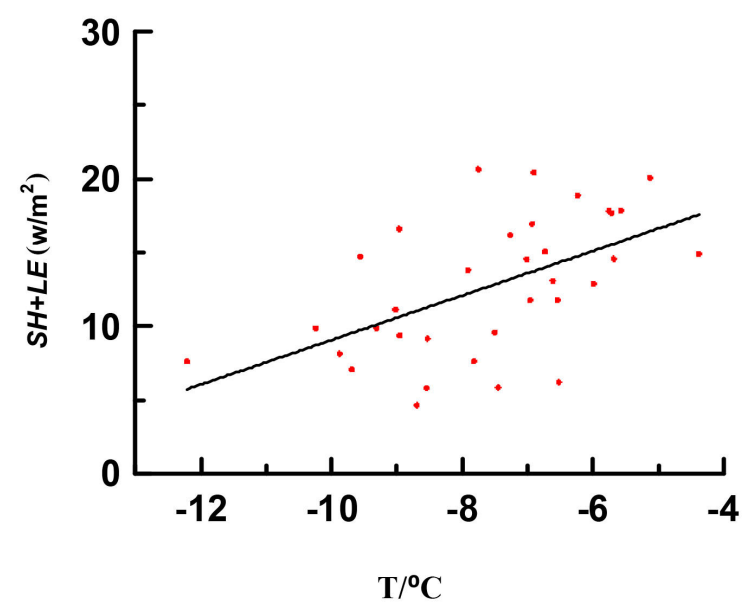

Figure 10. Correlation between average heat flux $(S H+L E)$ and temperature (T) at $2 \mathrm{~m}$ above sea level in the region $60^{\circ} \mathrm{N}$ in September of each year in 1979-2014. 
were closely related to sea-ice reduction. The interannual changes in sensible heat flux differed from those in latent heat flux. This condition may be because the sea-ice extent changed relatively unsubstantially (Figure 6), and the heat exchange among the sea, ice, and air was relatively weak in September of each year in 1995-2002. Reduction of the ice cover causes albedo changes, and increased refreezing of sea ice during the cold season and decreases in sea-ice thickness both increase heat flux from the ocean to the atmosphere.

Figure 9 and Figure 10 show correlations of the average heat flux (sensible heat flux + latent heat flux) with the percentage of sea-ice extent anomalies and the average temperature at $2 \mathrm{~m}$ above sea level in the region $60^{\circ} \mathrm{N}$ in September of each year in 1979-2014, respectively. These figures help display the relationship between sea-ice extent and heat flux. A considerable correlation was observed between heat flux and sea-ice extent in the Arctic. When the sea-ice extent decreased, the heat flux in the Arctic increased. The correlation coefficient between heat flux and sea-ice extent was 0.61 (sample size: 35 ) and reached a 99\% confidence level. In addition, a close relationship was observed between heat flux and temperature in the Arctic. Their correlation coefficient was 0.55 (sample size: 35 ) and surpassed the $99 \%$ confidence level. This finding means that an increase in heat flux will lead to an increase in surface temperature in the Arctic.

\section{Results and Discussion}

In this paper a new understanding of changes in radiation and heat flux and the role of sea-ice-air interactions in climate change in the central Arctic is expressed on the basis of data obtained during the six Chinese Arctic Research Expeditions and the reanalysis data. The main results are as follows:

1) Considerable diurnal and interdiurnal changes occur in solar radiation, albedo, and net radiation flux on the surface of Arctic sea ice. The surface of the Arctic sea ice has a high albedo and the average albedo varies from 0.74 to 0.86 . The melting process reduces the albedo and increases the absorption capacity of solar energy.

2) Similar to solar radiation, considerable diurnal and interdiurnal changes occurred in net sea-ice surface radiation flux in the Arctic. Due to the northernmost latitude of the ice station in 1999, the average net radiation flux measured was the highest. The average net radiation fluxes measured in 2012 and 2014 were relatively low due to the relatively high albedo of the sea-ice surface and weather factors.

3) Estimates of the surface heat flux in the third and the fourth Arctic are obtained using eddy correlation. The average sensible heat fluxes measured at the ice stations during the 2008 and 2010 observation periods were -1.51 and -1.89 $\mathrm{W} / \mathrm{m}^{2}$, and the average latent heat fluxes were 2.41 and $1.5 \mathrm{~W} / \mathrm{m}^{2}$, respectively. The radiation energy absorbed by the Arctic sea-ice surface is mainly consumed by ice melting and heat transfer in ice, and a small proportion participates in heat exchange with the atmosphere. 
4) The heat flux in the Arctic is highly sensitive to changes in the sea-ice extent. The characteristics of interdecadal changes in sensible and latent heat fluxes were found to be similar to those in sea-ice extent. When sea ice was remarkably reduced, the heat flux was considerably higher in 2001-2014 than in 1979-2000, particularly at the edges of the central Arctic Ocean. In September of each year in 1979-2014, the sea-ice extent was considerably correlated to the heat flux (sensible heat flux + latent heat flux) and atmospheric temperature at $2 \mathrm{~m}$ above sea level.

These results show the heat balance and sea-ice-air interactions in the central Arctic Ocean. The surface of the Arctic sea ice has a high albedo and high net radiation flux, which will be effected by the melting and reduction of sea ice. The correlation of the heat flux and sea ice extent demonstrates that the reduction of Arctic sea ice will lead to changes in heat flux, thereby warming the atmosphere and increasing the temperature of the atmospheric boundary layer over the Arctic. In addition, this impact is long-lasting. This study only displayed the relationship between changes in heat flux caused by the reduction of Arctic sea ice and temperature increases. Further research is needed to examine the apparent phenomenon that the continuous reduction of Arctic sea ice results in an increase in the ice-free area and consequently in additional radiation energy being absorbed by the ocean.

\section{Acknowledgements}

Thanks for all staffs of the Arctic Expedition for their kind help during the experiments.

\section{Foundation Item}

The National Basic Research Program (973 Program) of China (No. 2015CB953900) and the National Natural Science Foundation of China (No. 41330960, No.41776192).

\section{Conflicts of Interest}

The authors declare no conflicts of interest regarding the publication of this paper.

\section{References}

[1] Levitus, S. (2010) Warming of the World Ocean, 1955-2009. EGU General Assembly Conference, Vienna, 2-7 May 2010, 2861.

[2] Levitus, S., Antonov, J.I., Wang, J., et al. (2001) Anthropogenic Warming of Earth's Climate System. Science, 292, 267-270. https://doi.org/10.1126/science.1058154

[3] Levitus, S., Antonov, J. and Boyer, T. (2005) Warming of the World Ocean, 1955-2003. Geophysical Research Letters, 32, 59-70. https://doi.org/10.1029/2004GL021592

[4] Gille, S.T. (2002) Warming of the Southern Ocean since the 1950s. Science, 295, 1275-1277. https://doi.org/10.1126/science.1065863

[5] Willis, J.K., Roemmich, D. and Cornuelle, B. (2004) Interannual Variability in Up- 
per Ocean Heat Content, Temperature, and Thermosteric Expansion on Global Scales. Journal of Geophysical Research Oceans, 109, Article ID: C12036.

[6] Hansen, J., Nazarenko, L., Ruedy, R., et al. (2005) Earth's Energy Imbalance: Confirmation and Implications. Science, 308, 1431-1435.

https://doi.org/10.1126/science.1110252

[7] Screen, J.A. and Simmonds, I. (2010) The Central Role of Diminishing Sea Ice in Recent Arctic Temperature Amplification. Nature, 464, 1334-1337. https://doi.org/10.1038/nature09051

[8] Zhao, J., Shi, J., Wang, Z., et al. (2015) Arctic Amplification Produced by Sea Ice Retreat and Its Global Climate Effects. Advances in Earth Science, 30, 985-995. (In Chinese)

[9] Bian, L.G., Wang, J.Z., Sun, Y.L., et al. (2014) Sea Ice Drifting and Atmospheric Processes over the Central Arctic Ocean. Acta Oceanologica Sinica, 36, 48-55. (In Chinese)

[10] Steele, M., Zhang, J. and Ermold, W. (2010) Mechanisms of Summertime Upper Arctic Ocean Warming and the Effect on Sea Ice Melt. Journal of Geophysical Research Oceans, 115, Article ID: C11004. https://doi.org/10.1029/2009JC005849

[11] Lique, C. and Steele, M. (2013) Seasonal to Decadal Variability of Arctic Ocean Heat Content: A Model-Based Analysis and Implications for Autonomous Observing Systems. Journal of Geophysical Research Oceans, 118, 1673-1695. https://doi.org/10.1002/jgrc.20127

[12] IPCC (2007) Climate Change 2007. The Physical Scientific Basis. Working Group I Contribution to the Fourth Assessment Report of the Intergovernmental Panel on Climate Change. Cambridge University Press, Cambridge, UK, 997-1008.

[13] Shu, Q., Qiao, F.L. and Song, Z.Y. (2013) The Hindcast and Forecast of Arctic Sea Ice from FIO-ESM. Acta Oceanologica Sinica, 35, 37-45. (In Chinese)

[14] Qiu, B., Zhang, L.J., Chu, M., et al. (2015) Performance Analysis of Arctic Sea Ice Simulation in Climate System Models. Chinese Journal of Polar Research, 27, 47-55. (In Chinese)

[15] Fang, Y.J., Chu, M., Wu, T.W., et al. (2017) Couping of CICE5.0 with BCC_CSM2.0 Model and Its Performance Evaluation on Arctic Sea Ice Simulation. Acta Oceanologica Sinica, 39, 33-43. (In Chinese)

[16] Uttal, T., Curry, J.A., Mcphee, M.G., et al. (2002) Surface Heat Budget of the Arctic Ocean. Bulletin of the American Meteorological Society, 83, 255-276. https://doi.org/10.1175/1520-0477(2002)083<0255:SHBOTA >2.3.CO;2

[17] Vihma, T., Jaagus, J., Jakobosn, E., et al. (2008) Meteorological Condition in the Arctic Ocean in Spring and Summer 2007 as Recorded on the Drifting Ice Station Tara. Geophysical Research Letters, 35, 1-5. https://doi.org/10.1029/2008GL034681

[18] Hoinka, K.P. (1998) Statistics of the Global Tropopause Pressure. Monthly Weather Review, 126, 3303-3325. https://doi.org/10.1175/1520-0493(1998)126<3303:SOTGTP >2.0.CO;2

[19] Randel, W.J., Wu, F. and Forster, P. (2007) The Extratropical Tropopause Inversion Layer: Global Observations with GPS Data, and a Radiative Forcing Mechanism. Journal of the Atmospheric Sciences, 64, 4489-4496. https://doi.org/10.1175/2007JAS2412.1

[20] Han, Z., Bo, Z.L., et al. (2001) Arctic Upper Air Observations on Chinese Arctic Research Expedition 1999. Polar Meteorology and Glaciology, 15, 141-146.

[21] Hou, Q.S., Bo, Z.L., et al. (2002) Experiment of Planetary Boundary Layer Structure 
in Period of the Polar Day over Arctic Ocean. Chinese Journal of Geophysics, 45, 8-16.

[22] Chen, L., Zhao, J., Bian, L., et al. (2003) Study on Key Processes Affecting Rapid Changes in the Arctic. Chinese Journal of Polar Research, 15, 284-302. (In Chinese)

[23] Bian, L.G., Lu, L.H. and Zhang, Z.H. (2007) Analyses of Structure of Planetary Boundary layer in Ice Camp over Arctic Ocean. Journal of Chinese Political Science, 18, 8-17.

[24] Zhang, Z. (2004) The Report of 2003 Chinese Arctic Research Expedition. China Ocean Press, Beijing, 202-203. (In Chinese)

[25] Ma, Y., Bian, L., Zhou, X., et al. (2011) Vertical Structure of Troposphere in the Floating Ice Zone over the Arctic Ocean. Acta Oceanologica Sinica, 33, 48-59. (In Chinese)

[26] Bian, L., Ding, M., Lin, X., et al. (2016) Structure of Summer Atmospheric Boundary Layer in the Center of Arctic Ocean and Its Relation with Sea Ice Extent Change. Science China Earth Sciences, 59, 1057-1065.

https://doi.org/10.1007/s11430-015-5238-8

[27] Zhang, H. (2009) The Report of 2008 Chinese Arctic Research Expedition. China Ocean Press, Beijing, 1-203. (In Chinese)

[28] Yu, G. (2011) The Report of 2010 Chinese Arctic Research Expedition. China Ocean Press, Beijing, 24-97. (In Chinese)

[29] Ma, D. (2013) The Report of 2012 Chinese Arctic Research Expedition. China Ocean Press, Beijing, 1-160. (In Chinese)

[30] Pan, Z. (2015) The Report of 2014 Chinese Arctic Research Expedition. China Ocean Press, Beijing, 1-134. (In Chinese)

[31] Bian, L., Lu, L., Gao, Z., et al. (2001) Estimation of the Energy Component on the Ice of the Arctic Ocean. Progress in Natural Science, 5, 492-498. (In Chinese)

[32] Bian, L., Gao, Z., Lu, L., et al. (2003) Observational Estimation of Heat Budgets on Drifting Ice and Open Water over the Arctic Ocean. Science in China (Series D), 46, 580-591. https://doi.org/10.1007/BF02984536

[33] Li, J., Bian, L., Gao, Z., et al. (2005) Comparison of the Estimating Methods of the Turbulence Flux over a Drifting Ice Surface in the Arctic Area. Journal of Glaciology and Geocryology, 27, 368-375.

[34] Bian, L., Ma, Y. and Lu, C. (2011) Experiment of Turbulent Flux near Surface Layer and Its Parameterizations on an Drift Ice over the Arctic Ocean. Acta Oceanologica Sinica, 33, 27-35. (In Chinese)

[35] Chen, L.Q. (2003) Study on the Oceanic Environment and Interaction between Ocean and Air over Arctic Region. China Ocean Press, Beijing, 1-339. (In Chinese) 